\title{
A novel intubation technique for tracheo- esophageal fistula in adults
}

Calvin L. Au MD,

S. Adrian White MD FRCPC, Raymer P. Grant MD FRCPC

Purpose: To describe a novel technique of tracheal intubation and ventilation in an adult patient with a large tracheoesophageal fistula at the level of the carina.

Clinical Features: A 59 yr old woman with squamous cell carcinoma of the esophagus developed a large $(2 \mathrm{~cm}$ diameter) tracheoesophageal fistula after radiotherapy. The level of her fistula precluded traditional use of a double-lumen endobronchial tube. Intubation and ventilation were managed with two endobronchial tubes. The ability to ventilate or collapse each lung individually was preserved and anesthesia and surgery proceeded uneventfully.

Conclusion: Double endobronchial intubation is described to manage anesthesia in an adult patient with a tracheoesophageal fistula at the level of the carina.

Objectif : Décrire une nouvelle technique d'intubation trachéale et de ventilation chez un adulte présentant une grande fistule trachéo-oesophagienne au niveau de la carène.

Eléments cliniques : Une femme de 59 ans atteinte d'un épithéliome malpighien de l'œsophage a développé une grande fistule (diamètre de $2 \mathrm{~cm}$ ) trachéo-œsophagienne à la suite de radiothérapie. Étant donné la localisation de la fistule, l'usage du tube endobronchique à double lumière était exclu. Lintubation et la ventilation ont été réalisées avec deux tubes endobronchiques. La possibilité de ventiler ou de collaber chaque poumon séparément a été ainsi préservée et l'anesthésie et la chirurgie se sont déroulées sans incident.

Conclusion : L'intubation endobronchique double a permis de procéder à l'anesthésie chez une patiente adulte qui présentait une fistule trachéo-œsophagienne à la hauteur de la carène.

From the Department of Anaesthesia, Vancouver General Hospital, University of British Columbia, Vancouver, British Columbia, Canada V5Z 4E3.

Address correspondence to: Dr. Calvin L. Au, Phone: 604-875-4575; Fax: 604-875-5344.

Accepted for publication March 17, 1999 


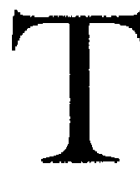

$\mathrm{HE}$ anesthesia management of patients with a tracheoesophageal fistula is challenging. Despite various techniques of managing the airway and ventilation, the common goal has been to avoid insufflating the stomach. We describe a novel technique to manage anesthesia in a patient with a tracheoesophageal fistula at the level of the carina.

\section{Case Report}

One year ago, a 59 yr old woman presented with increasing dysphagia and weight loss. She was subsequently diagnosed with poorly differentiated squamous carcinoma of the esophagus through imaging and biopsy. One month after the initial diagnosis, she was treated with a two month course of radical radiotherapy consisting of 4000 centigrays of external beam radiation and 1500 centigrays delivered via esophageal bougie. Palliative radiotherapy was chosen to reduce her stricture.

At that time, a feeding gastrostomy tube was placed to help the patient maintain her weight. Over the following months, she repeatedly developed esophageal strictures which were managed with intermittent esophageal dilatations. During a scheduled esophagoscopy and esophageal dilatation, the patient was noted to have a tracheoesophageal fistula. Interestingly, despite receiving gastrostomy feeds, this patient did not exhibit the typical symptoms of aspiration (e.g. coughing, dyspnea).

The tracheoesophageal fistula was approximately 2 $\mathrm{cm}$ in diameter and located at the level of the carina. It was delineated by repeat esophagoscopy and bronchoscopy (Figure 1). The patient's gastrostomy feeds were held and total parenteral nutrition was started. The patient was then scheduled for substernal gastroesophageal bypass with stapling of the proximal and distal esophagus. This surgical approach consists of a large substernal transverse incision and a supplementary incision on the left side of the neck close to the clavicle.

The patient was given supplemental oxygen via nasal prongs and monitored with ECG, pulse oximeter and arterial line. She was sedated with $1 \mathrm{mg}$ midazolam $i v$ and $50 \mu \mathrm{g}$ fentanyl $i v$. In the sitting position, a thoracic epidural at the level of $T_{7}$ was placed. The epidural catheter was tested with $3 \mathrm{~mL}$ bupivacaine $0.25 \%$ with $1: 200000$ epinephrine.

The patient was then returned to the supine position. Although the patient had not had gastrostomy feeds for almost a week and nothing by mouth for over a month, the gastrostomy tube was suctioned in an attempt to minimize any chance of aspiration:

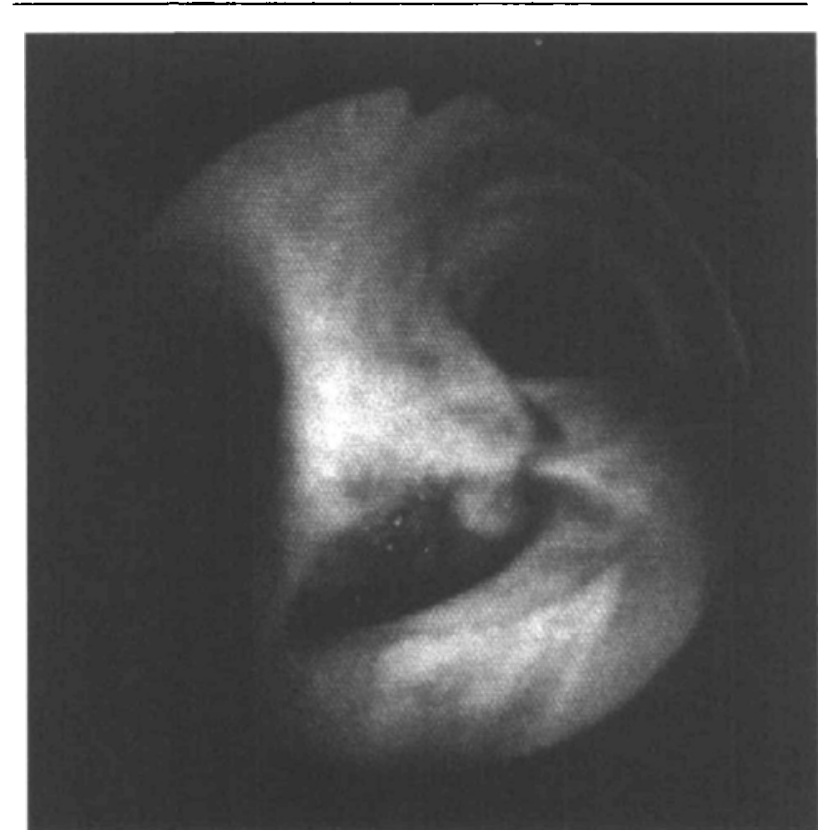

FIGURE 1 Bronchoscopic view showing tracheoesophageal fisrula at level of carina.

Then, an inhalational induction was performed with sevoflurane. Upon reaching an end-tidal sevoflurane level of $2.5 \%$, direct laryngoscopy was performed and $4 \mathrm{~mL}$ lidocaine $4 \%$ was sprayed onto her vocal cords and into her trachea. A deep level of anesthesia was ensured to prevent movement or breath-holding.

A cuffed 5.0 endotracheal tube (Mallinckrodt 320 $\mathrm{mm}$ microlaryngoscopy tube) was inserted into the trachea via direct laryngoscopy. Before cuff inflation, a fibreoptic intubating bronchoscope (Olympus LF-1) was passed through the vocal cords but external to the endotracheal tube. The tube was advanced further under direct fibreoptic vision into the right mainstem bronchus and adjusted so that the proximal part of the cuff could be seen at the carina (much like positioning the endobronchial cuff of a double-lumen tube). The cuff was then inflated and the circle circuit connected to the tube so the patient could continue to breathe oxygen and sevoflurane spontaneously through the single isolated right lung.

To isolate the left lung, the fibreoptic bronchoscope was loaded with an identical $\mathbf{5 . 0}$ cuffed microlaryngoscopy tube. The bronchoscope and endotracheal tube were then passed as a single unit through the vocal cords and into the left mainstem bronchus (Figure 2). Upon verification of correct position (beyond carina and proximal to the left upper lobe bronchus take-off), the second cuff was inflated. 


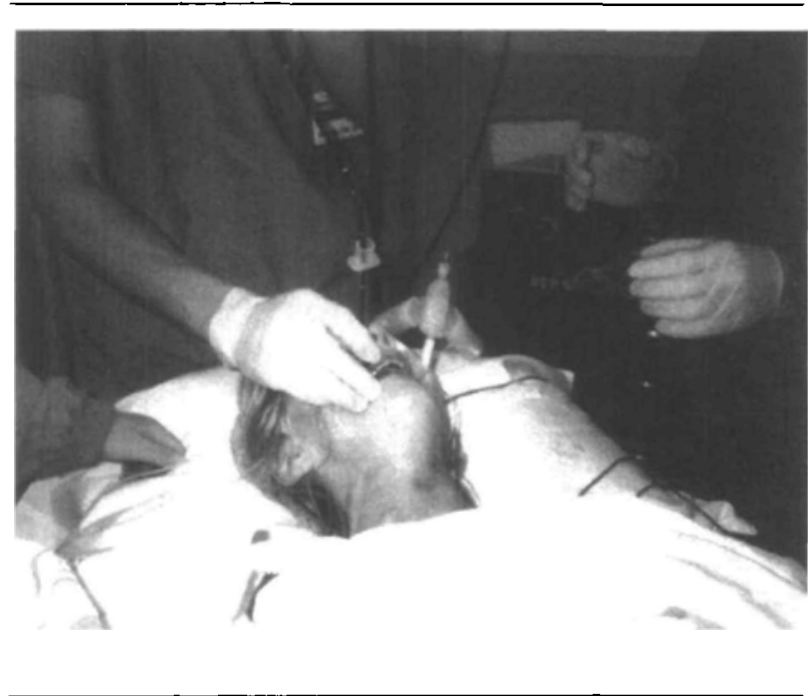

$\bar{F} \bar{I} \bar{U} \bar{R} \ddot{E} 2$ Fîbreoptic isolation of the left lung with ight lung already isolated and connected to circle circuit.

A standard Y-connector from a disposable doublelumen tube connected both endotracheal tubes simultaneously to the circle circuit. The ability to isolate each lung and ventilate with positive pressure without insufflating the stomach was confirmed. Muscle relaxation was then achieved with $50 \mathrm{mg}$ rocuronium and the parient's lungs were mechanically ventilated to a tidal volume of $400 \mathrm{~mL}$ and a rate of eight breaths per minute. Peak airway pressure was $22 \mathrm{~cm} \mathrm{H}_{2} \mathrm{O}$. Although no arterial blood gas analysis was performed, the $\mathrm{SpO}_{2}$ did not deviate from $99 \%$ with an $\mathrm{FiO}_{2}$ of 0.40 . The $\mathrm{P}_{\mathrm{ET}} \mathrm{CO}_{2}$ remained between 31 and $35 \mathrm{mmHg}$ while the lungs were ventilated.

Intermittent boluses of bupivicaine $0.25 \%$ were administered through the epidural catheter (total 15 $\mathrm{mL}$ ). To supplement the thoracic epidural, the patient received a balanced anesthetic of air/oxygen (50:50), desflurane (ET 3\%), rocuronium (total $100 \mathrm{mg}$ ), and $i v$ fentanyl (total $300 \mu \mathrm{g}$ ) over six hours.

The case proceeded uneventfully without the need for one lung ventilation and muscle relaxation was reversed with edrophonium and atropine. The patient's trachea was extubated in the operating room. There were no post-operative complications related to the placement of two endobronchial tubes.

\section{Discussion}

A Medline search from 1966 to the present was performed and this technique of double endobronchial intubation for ventilation management of tracheoesophageal fistula has not been reported. However, selective bronchial intubation has been previously reported in a case of distal tracheal rupture where one mainstem bronchus was intubated through the surgical field. ${ }^{1}$ Techniques to manage tracheoesophageal fistula include Z-stent placement, ${ }^{2}$ Fogarty balloon placement in the esophagus to plug the fistula, ${ }^{3}$ fibrin sealant usage, ${ }^{4}$ and high-frequency jet ventilation. ${ }^{5}$

Esophageal stenting has the advantage of being minimally invasive. However, its drawbacks include cost, varying survival characteristics, requirement of expertise, stent migration, and inadequate stent length. Most often, placement of a stent does not obviate the need for chemotherapy, radiation therapy or surgical placement of a gastrostomy or jejunostomy tube.

The placement of a Fogarty arterial embolectiomy catheter in the fistula is a well-documented method of dealing with tracheoesophageal fistula. The reported cases have been in neonatal patients. The size and shape of the fistula would also determine whether this would be a viable method. Lung separation would add another element of complexity with this technique of ventilation management. Fibrin sealant usage has also been described in the neonatal patient with tracheoesophageal fistula. A large fistula would certainly preclude this method of management.

Again, as in most of the methods previous mentioned, high frequency ventilation into one or both lungs has been described primarily for neonates. Drawbacks of this ventilation technique include the high risk of barotrauma. Also, delivered tidal volumes, however small, have a tendency to move from the trachea into the esophagus.

None of these previously described methods provide the versatility of double endobronchial intubation. With double intubation, the ability to ventilate each lung separately is preserved as is the option to collapse the right lung should a thoraco-abdominal approach become necessary. The possibility of providing CPAP to the collapsed lung to assist oxygenation is similarly retained. Finally, a suction catheter can be passed through either endobronchial tube for pulmonary toilet.

The primary advantage gained in this case was the ability to ventilate both lungs in the supine position. This surgical procedure, in the absence of a tracheoesophageal fistula, would usually only require a single lumen endotracheal tube. Invasion into the pulmonary cavity would have been managed with mechanically packing the lung aside. Had we chosen to use a double lumen tube, or a single lumen tube in the left main stem bronchus, then we would have been restricted to one lung ventilation due to the fistula's position at the carina which would have precluded the use of the tracheal lumen. One lung ventilation in the 
supine position would have been associated with greater intrapulmonary shunting than in the traditional lateral decubitus "thoracic" position as there would not have been the benefit of gravity-induced reduction of blood flow to the collapsed lung.

The drawbacks of placing two endobronchial tubes include the likelihood of occluding the right upper lobe bronchus and the increased difficulty with placement. Also, smaller patients may not have a glottis that would admit two endotracheal tubes. Tracheoesophageal fistula presents and challenge of airway control and ventilation but also presents the challenge of aspiration prevention. Fortunately, this patient's stomach was empty. This procedure could not have been done in an emergent situation or in a patient with a full stomach. It is a technique that requires both preparation and time.

In conclusion, there are many options to airway management in the patient with tracheoesophageal fistula. When the fistula is at the level of the carina, many of those disappear. The method that provides the most versatility is double endobronchial intubation.

\section{References}

I Lobato EB, Risley WP III, Stoltzfus DP. Intraoperative management of distal tracheal rupture with selective bronchial intubation. J Clin Anesth 1997; 9: 155-8.

2 Kozarek RA, Raltz S, Brugge WR, et al. Prospective multicenter trial of esophageal Z-stent placement for malignant dysphagia and tracheoesophageal fistula. Gastrointest Endosc 1996; 44: 562-7.

3 Reeves $S T$, Burt N, Smith $C D$. Is it time to reevaluate the airway management of tracheoesophageal fistula? Anesth Analg 1995; 81: 866-9.

4 Wiseman NE. Endoscopic closure of recurrent tracheoesophageal fistula using Tisseel. J Pediatr Surg 1995; 30: 1236-7.

5 Donn SM, Zak LK, Bozynski MEA, Coran AG, Oldbam $K T$. Use of high-frequency jet ventilation in the management of congenital tracheoesophageal fistula associated with respiratory distress syndrome. J Pediatr Surg $1990 ; 25$ : 1219-21. 